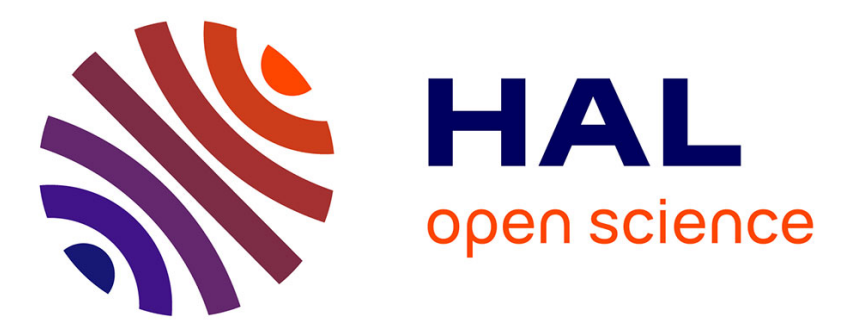

\title{
A new magnetoelastic resonance based technique to determine magnetomechanical parameters of amorphous ferromagnetic ribbons
}

Yannick Le Bras, A. Lasheras, J. Guttierez, Frederic Mazaleyrat, Jean-Marc Greneche

\section{To cite this version:}

Yannick Le Bras, A. Lasheras, J. Guttierez, Frederic Mazaleyrat, Jean-Marc Greneche. A new magnetoelastic resonance based technique to determine magnetomechanical parameters of amorphous ferromagnetic ribbons. Review of Scientific Instruments, 2013, 84, pp.043904. 10.1063/1.4799177. hal-00823870

\section{HAL Id: hal-00823870 https://hal.science/hal-00823870}

Submitted on 18 May 2013

HAL is a multi-disciplinary open access archive for the deposit and dissemination of scientific research documents, whether they are published or not. The documents may come from teaching and research institutions in France or abroad, or from public or private research centers.
L'archive ouverte pluridisciplinaire HAL, est destinée au dépôt et à la diffusion de documents scientifiques de niveau recherche, publiés ou non, émanant des établissements d'enseignement et de recherche français ou étrangers, des laboratoires publics ou privés. 


\title{
A new magnetoelastic resonance based technique to determine magnetomechanical parameters of amorphous ferromagnetic ribbons
}

\author{
Y. Le Bras ${ }^{1}$, A. Lasheras ${ }^{2}$, J. Gutierrez ${ }^{2}$, F. Mazaleyrat ${ }^{3}$, J.M. Greneche ${ }^{1}$ \\ ${ }^{1}$ LUNAM, Institut des Molécules et Matériaux du Mans, UMR CNRS 6283, Université du Maine, \\ F-72085 Le Mans Cedex 9, France \\ ${ }^{2}$ Facultad de Ciencias, Departamento de Electricidad y Electronica, Universidad del Paıs Vasco, Apartado 644, \\ E-48080 Bilbao, Spain \\ ${ }^{3}$ SATIE, ENS Cachan, CNRS, UniverSud, 61 av President Wilson, \\ F-94230 Cachan, France \\ yannick.lebras@univ-lemans.fr
}

\begin{abstract}
Measurement of the magnetomechanical parameters characteristics of amorphous ribbons often requires complex or limited methods due to their very small thickness. In this paper, it is shown how one can establish and estimate the characteristics of a magnetostrictive resonator from the experimental frequency response free of any kind of mechanical measurement (stress or elongation). This technique which is completely developed with a ribbon, exhibiting good resonator properties, is suitable to estimate the $\mathrm{k}_{33}$ magnetomechanical coupling coefficient and the Young's modulus and also to establish the magnetostriction curves $\lambda(\mathrm{H})$ of amorphous ribbons. Results obtained from resonators made of 2605SC and 2826 from Metglas ${ }^{\mathrm{TM}}$ ribbon confirmed the validity of the present technique. However, measurements performed on a thin foil of nickel demonstrate that the present method cannot be extended to semi-soft magnetic materials. The technique which is proposed has serious advantages upon others as it is non-destructive, low cost and easy to develop compared to common ones.
\end{abstract}

Keywords: magnetostrictive resonator, magnetomechanical coupling coefficient, frequency response, magnetostriction curve

Short Title: A new technique to study magnetomechanical properties of ribbons 


\section{Introduction}

The magnetostrictive resonators which can be used as a transducer emitting or sensing elastic waves, have been early developed in 60's and then characterized for 20 years, with special attention to the magnetomechanical coupling coefficient denoted $k_{33}$ [1-4]. However, the estimation of $\mathrm{k}_{33}$ is difficult and remains a lock for technological applications of magnetostrictive materials.

The magnetostriction effect is revealed by the change in length of a ferromagnetic sheet when it is magnetized, as a consequence of the spin-orbit coupling at the atomic local scale. It is now well established that most of ferromagnetic metallic glasses exhibit magnetostrictive properties rather similar to those of their crystalline counterparts, except that they show very low magnetic anisotropy and near-perfect elasticity resulting from the lack of long range order, these figures making them ideal candidates for magnetoelastic applications.

Since Joule's experiments in 1842, many different methods where developed to measure the magnetostriction. However, they are not well adapted to amorphous ribbons due to their mechanical behaviour. Indeed, as they are so thin, length measurement sensors (using mechanical contact) or strain gauges (thicker than the ribbons) usually affects greatly the quality of the measurement. Indeed, such an approach which requires that the gauge is glued to the sample, so itcannot be used as a routine measurement technique, it should affect the elastic properties and will not provide any estimation of the magnetomechanical coupling coefficient. In the case of optical measurements where the changes of sample length are dependent on the optical power transmitted to an optical fiber, the ribbon needs a minimum mechanical load, inducing thus some disturbance of magnetoelastic properties. In addition, this method as well as that based on the capacitance effect does not allow the magnetomechanical coupling coefficient to be estimated. Alternative technique could be the small angle magnetization rotation (SAMR) method [5] widely used for amorphous and nanocrystalline ribbons: this method is very accurate for those materials but provides only the estimation of saturation coefficient $\lambda_{\mathrm{s}}$.

As earlier reported [1], the magnetoelastic resonance is a good method to measure magnetomechanical coupling coefficient. The resonator consists in an exciting coil producing an alternating magnetic field along the ribbon which in turn induces a longitudinal elastic wave in the ribbon. The magnetostriction coefficient can be approximately estimated from resonance and antiresonance frequencies but the mechanical losses were not taken into account. We recently proposed a complete model of the magnetostrictive resonator [6] that makes possible the development of the new experimental technique reported in the present paper. The improvement described herein is based on the fitting of the experimental frequency response taking mechanical losses into account. The increase in the number of fitting parameter is compensated by the much larger quantity of information and thus, allows the fine determination of coupling coefficient and magnetostriction as a function of exciting field.

The aim of this paper is to demonstrate in what extend this new technique is suitable to characterize magnetostrictive resonator and to determine both $\lambda(\mathrm{H})$ curve and magnetomechanical coupling coefficient $\mathrm{k}_{33}$. Then, the validation of the procedure was established on the basis of measurements conducted on selected amorphous ribbons and a crystalline nickel foil as standard. Finally, comparison of the present approach with current methods shows easier and cheaper development and that our method can be considered as the first bringing accurate evaluation of magneto-mechanical parameters among routine measurement techniques applicable to amorphous ribbons. 


\section{Model and parameters}

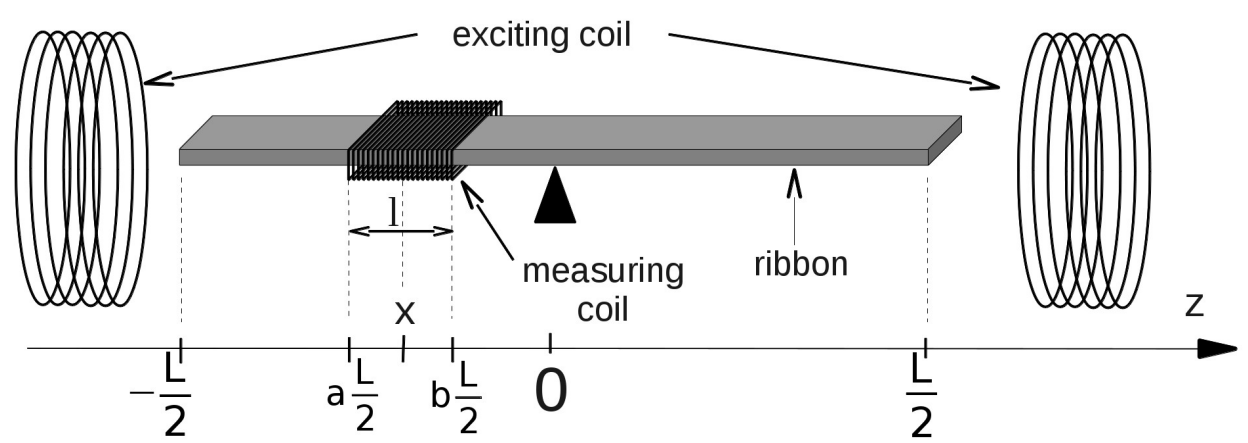

Figure 1: Principle of a ribbon shaped resonator (L: ribbon length ; l : pick-up coil length)

The measurements discussed below were performed using a set-up close to that presented in [6]. After [6], the frequency response of the magnetostrictive resonator (given in eq 1) is defined as the output/input coils voltage ratio when submitted to an electrical excitation.

$$
T=1+2 \frac{k_{33}{ }^{2}}{1-k_{33}{ }^{2}} \frac{E_{r 0}+j E_{i 0}}{I(b-a)} \frac{e^{\left(-K_{i}+j K_{r}\right) a \frac{1}{2}}+e^{\left(K_{i}-j K_{r}\right) b \frac{1}{2}}-e^{\left(-K_{i}+j K_{r}\right) b \frac{1}{2}}-e^{\left(K_{i}-j K_{r}\right) a \frac{1}{2}}}{K_{i}-j K_{r}}
$$

where:

the dimentionless parameters a and $b$ : define the size and position of the pick-up coil (see fig 1); $k_{33}$ : (dimensionless) the magnetomechanical coupling coefficient, and $\mathrm{K}_{\mathrm{r}}$ et $\mathrm{K}_{\mathrm{i}}$ are real and imaginary parts of the wave vector $\mathrm{k}$, expressed as:

$$
\begin{aligned}
& K_{r}=\frac{\sqrt{\frac{\rho}{Y}} \omega}{\sqrt[4]{1+\eta^{2}}} \cos \left(\frac{\operatorname{tg}^{-1}(\eta)}{2}\right) \\
& K_{i}=-\frac{\sqrt{\frac{\rho}{Y}} \omega}{\sqrt[4]{1+\eta^{2}}} \sin \left(\frac{\operatorname{tg}^{-1}(\eta)}{2}\right) \\
& E_{r O}=\frac{e^{\frac{3 k_{i} L}{2}}+3 e^{\frac{k_{i} L}{2}}+3 e^{-\frac{k_{i} L}{2}}+e^{-\frac{3 k_{i} L}{2}}-4 e^{\frac{k_{i} L}{2}} \cos ^{2}\left(\frac{k_{r} L}{2}\right)-4 e^{-\frac{k_{i} L}{2}} \cos ^{2}\left(\frac{k_{r} L}{2}\right)}{e^{2 k_{i} L}-2+e^{-2 k_{i} L}+16 \cos ^{2}\left(\frac{k_{r} L}{2}\right)-16 \cos ^{4}\left(\frac{k_{r} L}{2}\right)} \cos \left(\frac{k_{r} L}{2}\right) \\
& E_{i 0}=\frac{e^{\frac{3 K_{i} l}{2}}+e^{\frac{K_{i} l}{2}}-e^{-\frac{K_{i} l}{2}}-e^{-\frac{3 K_{i} l}{2}}-4 e^{\frac{K_{i} l}{2}} \cos ^{2}\left(\frac{K_{r} l}{2}\right)+4 e^{-\frac{K_{i} l}{2}} \cos ^{2}\left(\frac{K_{r} l}{2}\right)}{e^{2 K_{i} l}-2+e^{-2 K_{i} l}+16 \sin ^{2}\left(\frac{K_{r} l}{2}\right) \cos ^{2}\left(\frac{K_{r} l}{2}\right)} \sin \left(\frac{K_{r} l}{2}\right)
\end{aligned}
$$

where $\rho$ is the specific mass, $\omega$ the angular velocity $\omega=2 \pi \mathrm{f}$, and $\eta$ is a damping factor characteristic of the resonator introduced in the expression of complex Young's modulus:

$\bar{Y}=Y(1+j \eta)$ 
Note that $f_{0}$ corresponds to the resonant frequency.

The polarization field is supposed to be uniform over the total length of the ribbon, with two components $\mathrm{H}_{\mathrm{DC}}$ and $\tilde{H} . \mathrm{H}_{\mathrm{DC}}$ is the DC bias polarization field and $\tilde{H}$ the alternative excitation field, low enough to make the effects of hysteresis negligible.

\section{Output voltage}

The output is $\mathrm{V}_{\mathrm{M}}$, the rms voltage across the pick-up coil is defined as

$$
V_{M}=V_{\text {Mexc }} \cdot T=V_{M 0} \cdot\left(1-k_{33}{ }^{2}\right) \times\left(1+2 \frac{k_{33}{ }^{2}}{1-k_{33}{ }^{2}} \frac{E_{r 0}+j E_{i 0}}{L(b-a)} \frac{e^{\left(-K_{i}+j K_{r}\right) a \frac{L}{2}}+e^{\left(K_{i}-j K_{r} \mid b \frac{L}{2}\right.}-e^{\left(-K_{i}+j K_{r}\right) b \frac{L}{2}}-e^{\left(K_{i}-j K_{r}\right) a \frac{L}{2}}}{K_{i}-j K_{r}}\right)
$$

with

$$
V_{M 0}=\frac{V_{M e x c} \cdot 2 n_{b}^{2} S}{L(b-a)} \cdot \frac{\mu_{33}{ }^{\sigma}}{L_{\text {exc }}}
$$

where $V_{\text {Mo}}, V_{\text {Mexc }}, n_{b}$ and $L_{\text {exc }}$ are the static voltage, the excitation coil rms voltage, the number of turns and the inductance of the excitation coil, respectively. $\mathrm{S}$ is the cross section of the ribbon and $\mu_{33}{ }^{\sigma}$ is the permeability at constant strain.

$\mu_{33}{ }^{\sigma}$ can be estimated using the $\mathrm{B}(\mathrm{H})$ curve measured for the free ribbon using the relation:

$$
\mu_{33}{ }^{\sigma}=\left(\frac{d B}{d H}\right)_{\sigma=0}
$$

One concludes that the rms voltage $V_{M}$ is dependent on $V_{M 0}, a, b, L, k_{33}, \rho, Y, \eta$ and $f$. It is easy to estimate the geometrical characteristics of the ribbon (a, b, L, and $\rho$ ). But the 4 remaining parameters $\left(V_{\mathrm{M} 0}, k_{33}, \eta\right.$ and $\mathrm{Y}$ ) have to be fitted from the experimental frequency response.

\section{Experiment}

\section{1 experimental set-up}

bias coil $11000 \mathrm{~A} / \mathrm{m} / \mathrm{A}, \mathrm{L}=245 \mathrm{~mm}, \varnothing=104 \mathrm{~mm}$

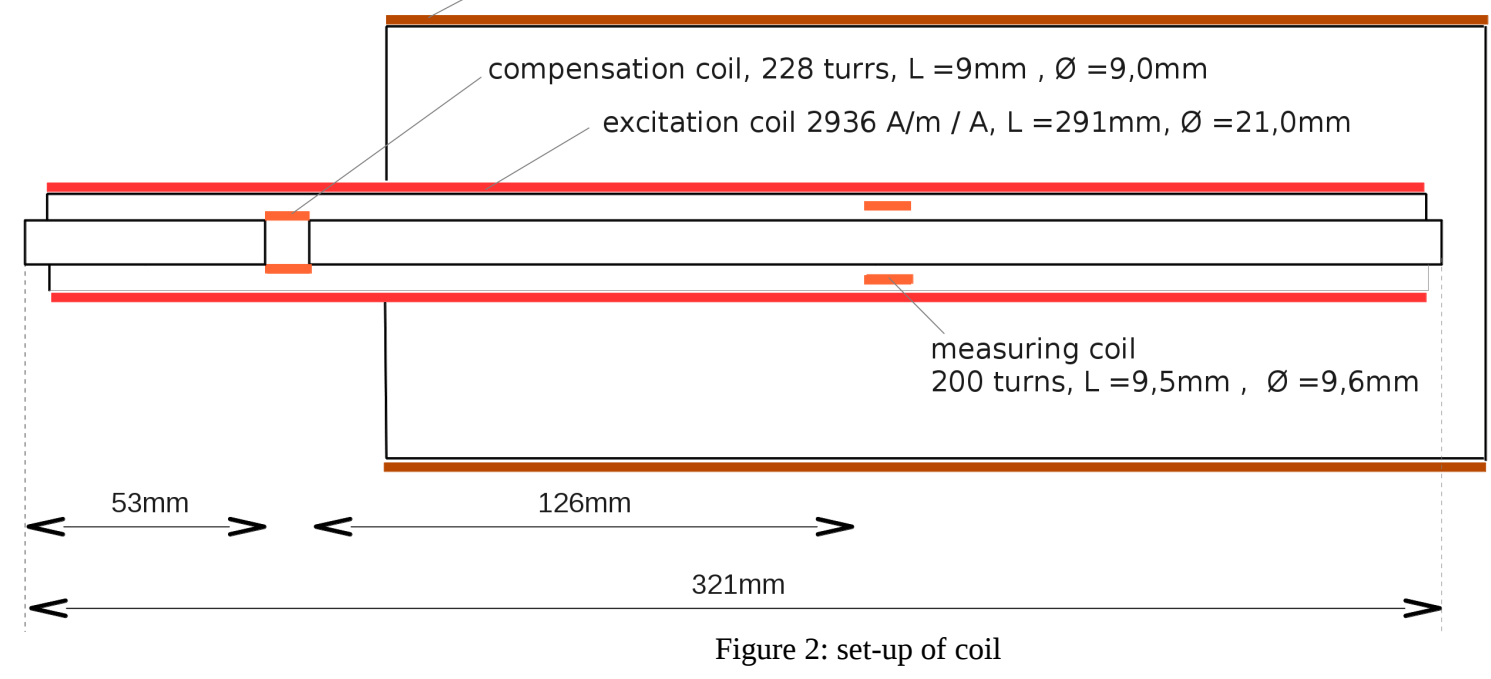




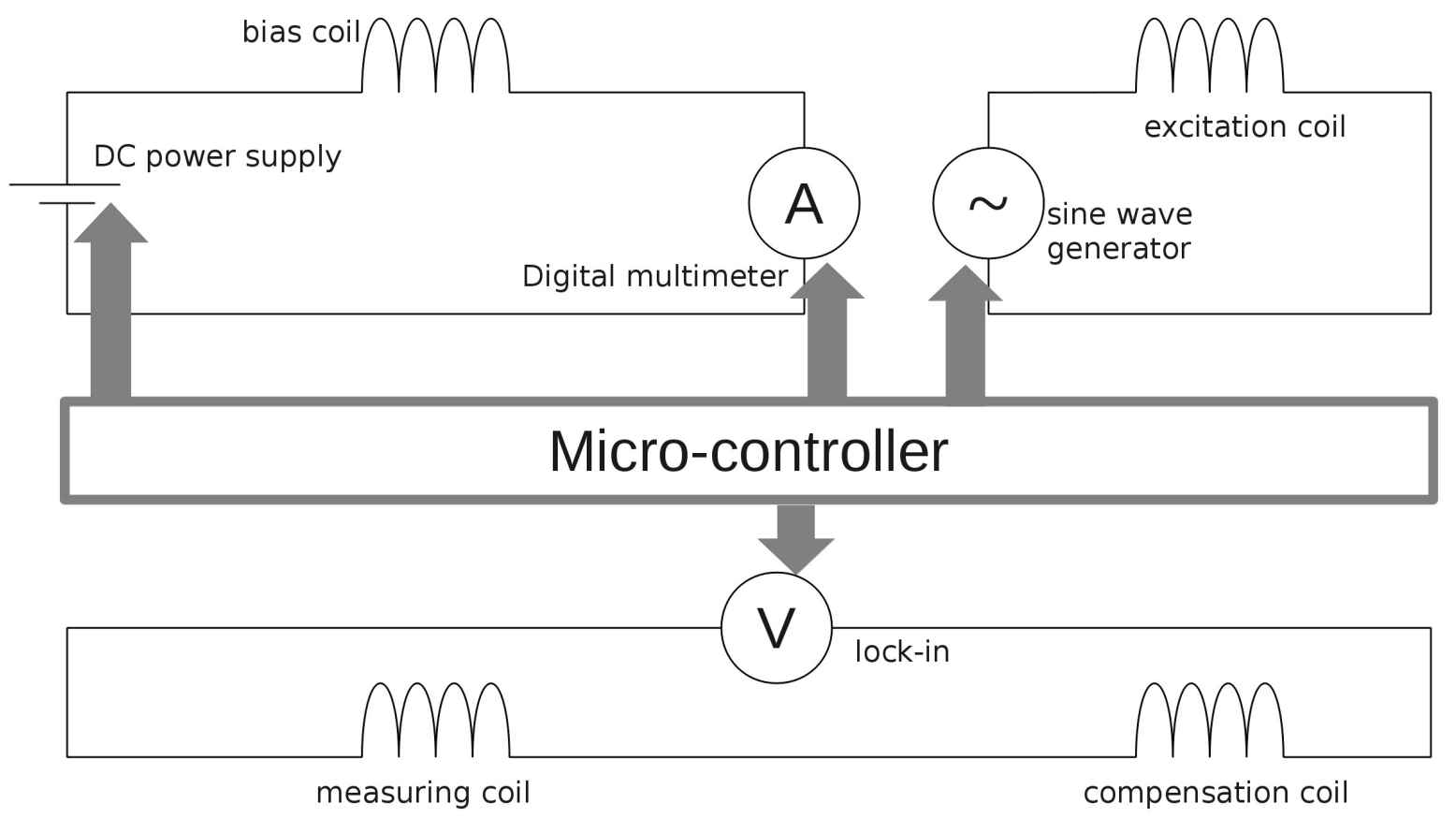

Figure 3 : set-up controller

The experimental set-up for measuring the magnetoelastic resonance, describe elsewhere [7], has been originally designed to study magnetoelastic properties of metallic glasses [8-9]. It consists in two, $1 \mathrm{~cm}$ long pick-up coils, for detection and for compensation, centered inside a 19$\mathrm{cm}$ long solenoid for the excitation and polarization, since it is well established that a uniform polarization field is achieved using rather a long solenoid than an Helmholtz coils set.

The set-up comprises DC source, multimeter and an analyser computer-controlled with HP VEE Visual Programming Language. A network analyser (HP 3589A spectrum/network analyser equipped with 5-test option) records the output voltage as a function of the frequency.

The ribbon shaped resonator is set on the middle of a Teflon plate in lying on a half-pipe removable from the coils.

\subsection{Resonators}

Different amorphous ribbons as Metglas $^{\mathrm{TM}} 2605 \mathrm{SC}$ and 2826 were studied, as well as a NiFeCo-based amorphous ribbon taken from a magnetoelastic anti-theft label and, finally, a thin crystalline $\mathrm{Ni}$ foil for comparison. It is important to mention that the NiFeCo ribbon was first considered because it's ready to use and industrially optimized (from composition and processing point of view) for the magnetoelastic resonance measurements. The chemical composition was analysed by X-ray fluorescence and EDX yielding approximately the composition as $\mathrm{Ni}_{46} \mathrm{Fe}_{24} \mathrm{Co}_{12} \mathrm{~B}_{16} \mathrm{Si}_{2}$. We are inclined to think that this ribbon was prepared by Vacuumschmelze $\mathrm{GmbH}[10,11]$. Then Metglass 2826 was chosen as it remains the most used in the design of magnetostrictive resonator while 2605SC is the highest magnetostrictive amorphous material with a magnetomechanical coupling coefficient estimated at 0,97 [12]. Finally, Ni foil was tested to check the validity range of the model, as a crystalline and less soft magnetic material.

As the resonance frequency is proportional to the inverse length, a sharp resonance requires the sample to be perfectly rectangular. The as-quenched 2605SC and 2826 ribbons are $12,7 \mathrm{~mm}$ in width. Thus, the cutting has to be done with caution, using a diamond wire saw. The ribbons were stick on plastic plates with dental wax and then cut. But this method fails in the case of 2605SC ribbon for which a good cutting was achieved by laser impulsion. Finally, the geometrical characteristics of the different samples are the following: - 2605SC $\left(\mathrm{Fe}_{81} \mathrm{~B}_{13.5} \mathrm{Si}_{3.5} \mathrm{C}_{2}\right)$ : 30mm long, $6 \mathrm{~mm}$ width, $17,8 \mu \mathrm{m}$ thick and a density of $7320 \mathrm{~kg} / \mathrm{m}^{3}$, 
- $2826\left(\mathrm{Fe}_{40} \mathrm{Ni}_{40} \mathrm{P}_{14} \mathrm{~B}_{6}\right)$ : 30mm long, $6 \mathrm{~mm}$ width, $29,2 \mu \mathrm{m}$ thick and a density of $7900 \mathrm{~kg} / \mathrm{m}^{3}$, and, - NiFeCo: 37mm long, $6 \mathrm{~mm}$ width, $25 \mu \mathrm{m}$ thick and a density about $7400 \mathrm{~kg} / \mathrm{m}^{3}$. Note that the later ribbon did not require any preparation.

In addition, it is well established that the magnetostrictive properties of metallic glasses, which greatly depend on the internal stresses induced by the quenching process, could be improved after subsequent annealing treatment, without external magnetic field or under either longitudinal or transverse magnetic field. In order to maximize the magnetostriction, the ribbons have to be transverse field annealed. Indeed, as the domains will be transverse (thus perpendicular to exciting field) the magnetization process will be rotation only. Thus, as magnetostriction depends only on the squared sine of the angle of the magnetization with respect to easy axis, a uniform $90^{\circ}$ rotation will maximize the elongation.

Consequently, several samples were prepared under the following conditions:

- 2605SC for $2 \mathrm{~h}$ at $390^{\circ} \mathrm{C}$ under vacuum without field and with transverse field of $10 \mathrm{kA} / \mathrm{m}$, and for $10 \mathrm{~min}$ at $370^{\circ} \mathrm{C}$ with field of $800 \mathrm{kA} / \mathrm{m}$.

- 2826 for $2 \mathrm{~h}$ at $340^{\circ} \mathrm{C}$ under vacuum without field and with a transverse field of $10 \mathrm{kA} / \mathrm{m}$, and for $1 \mathrm{~h}$ at $340^{\circ} \mathrm{C}$ with a transverse field of $800 \mathrm{kA} / \mathrm{m}$.

The as-quenched and annealed ribbons were systematically studied by ${ }^{57} \mathrm{Fe}$ Mössbauer spectrometry at $300 \mathrm{~K}$ to check that no crystallization occurs and that the magnetic domains were slightly rotating in the ribbon plane according to the magnetic texture analysis after annealing due to relaxation of stresses[13][14][15].

Finally, to study the effect of the length, three samples of one composition, annealed under a transverse field of $10 \mathrm{kA} / \mathrm{m}$, were tested . For those ribbons, the length to width ratio was the same in order to discard the effect of the demagnetizing field. At last, the 0,25 mm thick Ni foil (purity 99\%) was cut by means of electrical discharge machining.

It is important to emphasize that the achievement of a good resonator requires to overcome the technical difficulties related to cutting of as-quenched and annealed ribbons.

\section{Proof of the model}

\subsection{Studying responses with harmonics}

The aim is first to check the ability of the model to fit experimental curves. For this purpose, we have chosen a NiFeCo based amorphous ribbon used as resonator in anti-theft label. Although its composition and magnetoelastic properties are not known, this ribbon is interesting because the industrial cutting process should in principle ensure its perfect rectangularity that gets out of the problem of parasitic resonances. The DC field is set such the pick-up voltage is as large as possible. The voltage spectrum is recorded as a set of 400 points on a linear frequency scale in the range between 50 and $350 \mathrm{kHz}$. Fitting allows to estimate the parameters of the model $-\mathrm{V}_{\mathrm{M} 0}, \mathrm{k}_{33}, \eta, \mathrm{f}_{0^{-}}$ using a least squared minimization procedure, providing that frequency $\mathrm{f}_{0}$ and Young modulus $\mathrm{Y}$ are correlated through following relation

$$
f_{0}=\frac{1}{2 L} \sqrt{\frac{Y}{\rho}}
$$



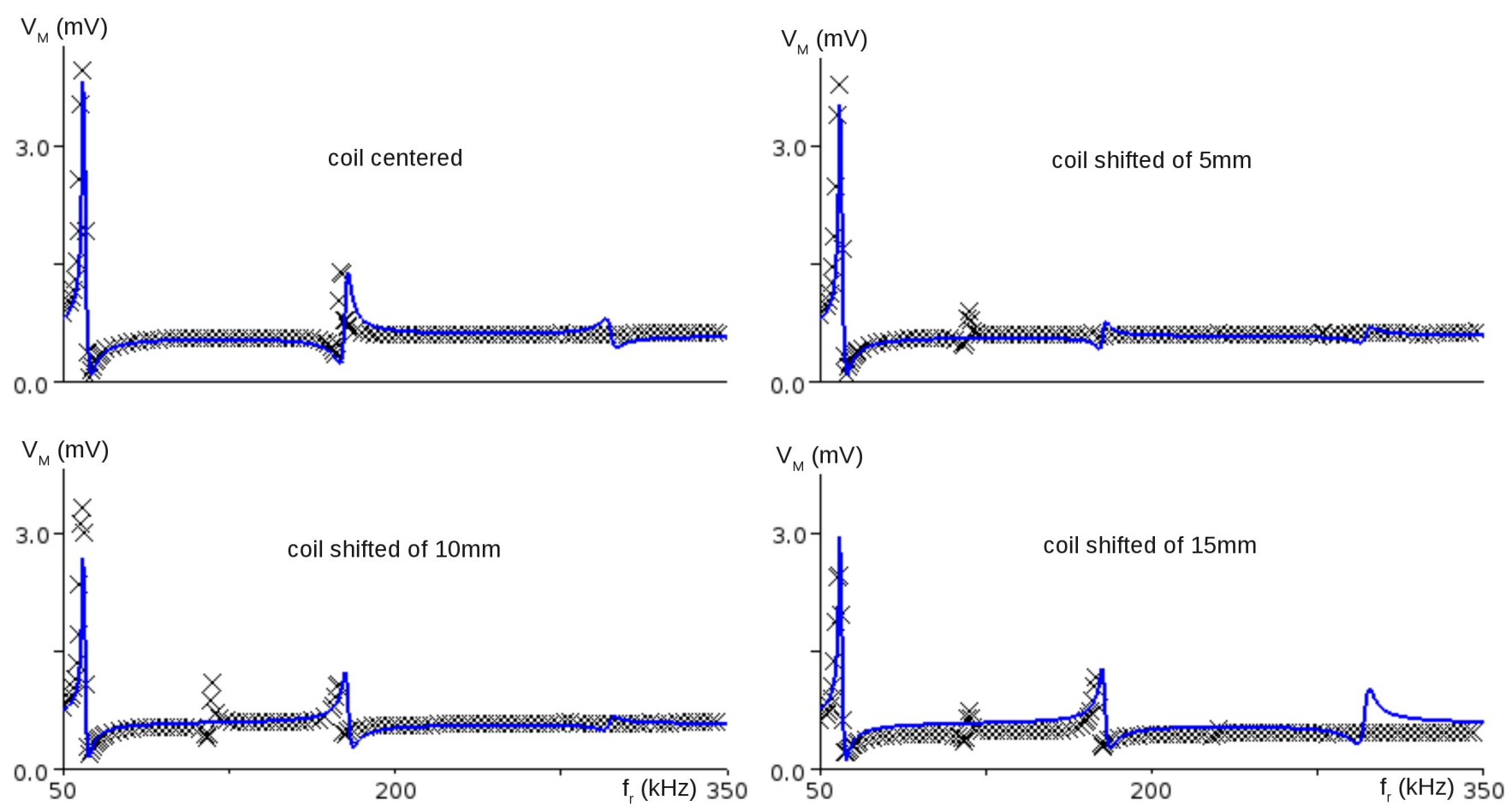

Figure 4: Amplitudes as function of the frequency: effect of the position of the pick-up coil, responses for coil centered, shifted of 5, 10 and $15 \mathrm{~mm}$

Different experimental conditions have been considered with four positions of the ribbon in the pick-up coil giving rise to four sets of $a$ and $b$ values.

The spectrum presented in figure 4 for the centred coil illustrates that the response around the fundamental and the prediction of anti-resonant/resonant $3^{\text {rd }}$ harmonic are satisfactory. The $5^{\text {th }}$ harmonic almost vanishes in the experiment presumably because of eddy currents which are obviously relevant at $300 \mathrm{kHz}$. For off-centered coils, the prediction of harmonic 3 vanishing or reversal (resonant/anti-resonant) is properly predicted. On the contrary, the presence of even harmonics is not predicted. They may result from either the non-uniformity of the field or the lack of symmetry of the sample since they are not seen when the coil is centred. The latter argument also eliminates the possibility of a second harmonic from the AC excitation.

From this model testing, it is concluded that it is perfectly adapted to the lower frequencies. The model of a damping constant $\eta$ is not appropriate for the larger frequencies. Indeed, a simple damping constant means that the losses (expressed in terms of energy) are constant. This is valid only when friction dominates the viscosity for mechanical losses and the hysteresis loss dominates the eddy current losses, which means that the lower the frequency is, the better the model. Of course, a linearly frequency dependent $\eta$ could improve the model, but only at the price of a additional parameter and still, would be unable to take the aerodynamic losses into account. These prliminary measurements allow to validate this model, providing that (i) the pick-up coil is centred on the ribbon, and (ii) the frequency range for the measurement of response is restricted close to the fundamental. Furthermore they provided a method to check if the whole set-up is properly centred and the sample symmetric, that is absolutely necessary for reproducible experiments.

\subsection{Characterization of the resonator ribbon}

The position of NiFeCo based ribbon located at the centre of the set-up was controlled by searching the minimum of the second harmonic. We report in Figure 5 the response corresponding to the maximum $k_{33}$ value. Using formula (e 7), we fit the values of parameters $V_{M 0}, k_{33}, \eta$, $f_{0}$ were fitted. One observes in Figure 5 an excellent description for frequencies near the first resonance. To validate the model and the physical consistency of deduced parameters, their evolution as a function 
of polarization was studied. Because the magnetostriction is maximal around the coercive field, hysteresis loop was established to define different values of DC fields to be applied.

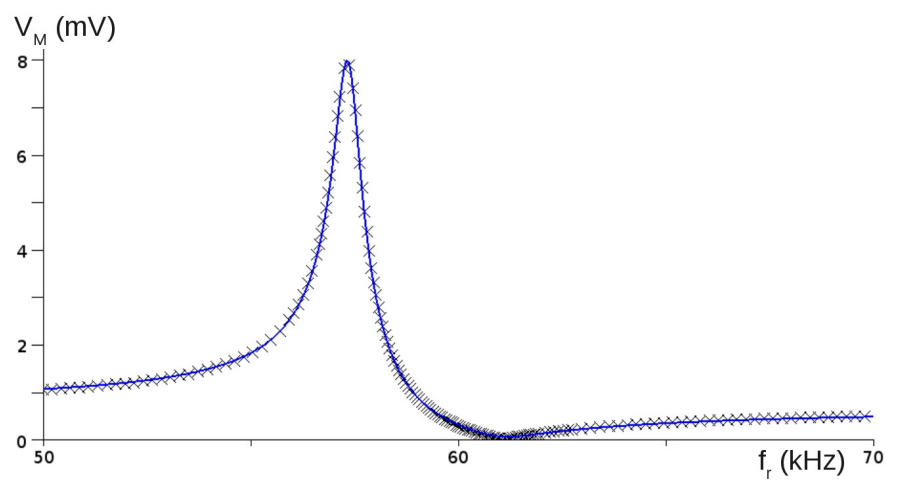

Figure 5: Amplitudes as function of the frequency for $610 \mathrm{~A} / \mathrm{m}$

Figure 6 illustrates the evolution of resonant and anti-resonant frequency $f_{r}$ and $f_{a}$, Young's modulus $\mathrm{Y}$, magnetomechanical coefficient $\mathrm{k}_{33}$, damping constant $\eta$, static voltage $\mathrm{V}_{\mathrm{M} 0}$, and amplitude of main resonance $\mathrm{V}_{\max }$. From the hysteresis loop the evolution of flux density $\mathrm{B}$ and its derivative, permeability $\mu$, can be also plotted.

The magnetomechanical coefficient is derived from Gibbs free energy, as early reported by Lacheisserie [16]:

$$
\mathrm{k}_{33}=\mathrm{d}_{33} \sqrt{\frac{\mathrm{Y}}{\mu_{33}{ }^{\sigma}}}
$$

Hence, from $k_{33}$, $Y$ and $\mu$ we can calculate the slope of the magnetostriction curves $d_{33}$ and get the strain after integration as shown in Fig.6.
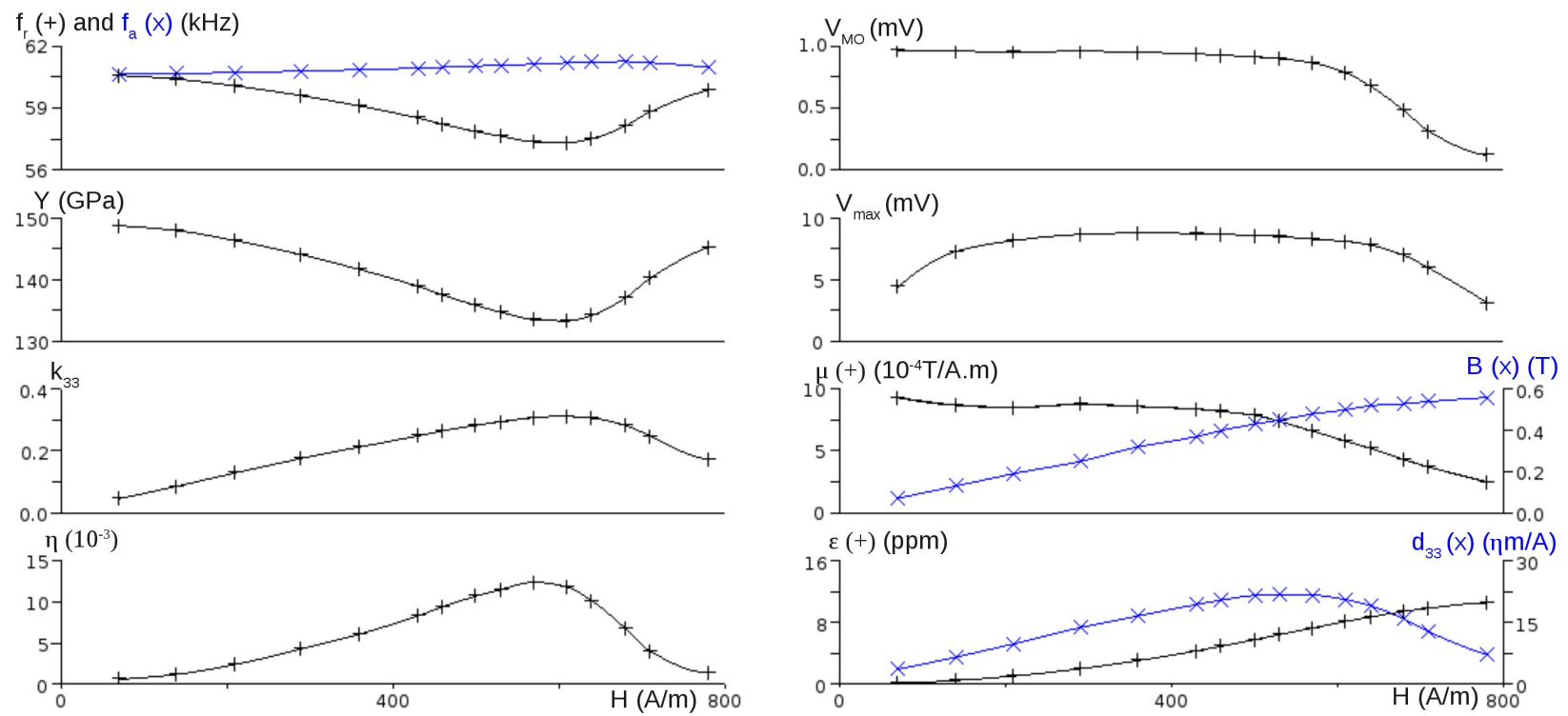

Figure 6: evolution of resonant and anti-resonant frequency $f_{r}$ and $f_{a}$, Young's modulus $Y$, magnetomechanical coefficient $k_{33}$, damping $\eta$, static voltage $V_{\text {Mo }}$, maximum of amplitudes $V_{\max }$, flux density $B$, permeability $\mu$, slope of the magnetostriction curves $d_{33}$ and strain $\varepsilon$ as function of DC field for NiFeCo ribbon. 
One first observes that (i) $f_{0}$ is very close to resonance frequency $f_{r}$, (ii) $f_{r}(H)$ exhibits a minimum in agreement with those found in the literature [9], (iii) Young's modulus range from 130 to $150 \mathrm{GPa}$ and its evolution versus polarization is as expected, (iv) anti-resonant frequency $\mathrm{f}_{\mathrm{a}}$ increases slightly with field (about $1 \%$ ), (v) both $\mathrm{V}_{\mathrm{M} 0}(\mathrm{H})$ and $\mu(\mathrm{H})$ remain rather constant for low polarization values and decrease when approaching to saturation.

Indeed, according to (e 8) $\mathrm{V}_{\mathrm{M} 0}$ is proportional to permeability $\mu_{33}{ }^{\sigma}$ obtained by differentiating $\mathrm{B}(\mathrm{H})$.

In addition, $\mathrm{V}_{\max }(\mathrm{H})$ does not behave as $\mathrm{k}_{33}(\mathrm{H})$ because of the dependence of $\mathrm{V}_{\max }$ on $\mathrm{V}_{\mathrm{M} 0}$. It is now important to emphasize that both the increase of $\mathrm{k}_{33}$ from 0 up to 0,31 and its decrease are satisfactory, and in agreement with the usual magnetostriction characteristics established on amorphous ribbons. The evolution of magnetostriction curve $\varepsilon(\mathrm{H})$ which derives from (e 9), is not often reported in literature, where the saturation value is mostly reported $[12,17]$.

The polarization dependence of $\eta(\mathrm{H})$, which corresponds to the ratio between the imaginary and real parts of Young's modulus, can not be interpreted on the basis of pure mechanical losses. On the contrary, the dependence observed makes sense if we interpret them as hysteresis loss. Indeed, for a small $\mathrm{H}_{\mathrm{AC}}$, hysteresis loss drops to zero when the DC field saturates the material. Furthermore, if one compares the value of $\eta(\mathrm{H})$ for zero and saturating DC field, losses seem to reach a background value of about $10^{-3}$ which presumably corresponds to mechanical losses. Thus, by opposition to the starting assumption, it seems that the loss parameter mainly corresponds to hysteresis loss, which is not so surprising since metallic glasses are nearly perfectly elastic. From practical point of view, the model is still valid providing the AC field is constant during the experiment and the frequency is low enough to neglect the eddy currents.

These preliminary results obtained on a NiFeCo based amorphous ribbon allow to conclude that the present method based on magnetoelastic resonance is suitable to measure magnetomechanical coupling coefficient $\mathrm{k}_{33}$, its dependence with $\mathrm{H}$, and then to establish the magnetostriction curve characteristic of a free ribbon: such an approach is new and easy to implement contrarily to usual procedures based on either optical [18], capacitive [19] or strain gauge [20] principles. This procedure is now going to be a applied to amorphous 2605SC and 2826 ribbons which magnetoelastic characteristics are well known.

\section{Measurements on 2605SC and 2826 ribbons}

\subsection{Measurements with 2605SC}

Similar measurements have been performed on as cast, zero-field and transverse-field annealed 2605SC ribbons (see section 3.2). It is to emphasize that the geometry of the ribbon has to be perfectly rectangular. The frequency response for $2605 \mathrm{SC}$ as cast ribbon at a polarization of $1350 \mathrm{~A} / \mathrm{m}$ is depicted in Figure 7. The secondary peaks which are associated to parasite modes, originated unambiguously from the presence of geometrical defaults. An accurate estimation of parameters requires thus to reduce parasitic resonances as much as possible and to have quite distant resonance and anti-resonance frequencies. 


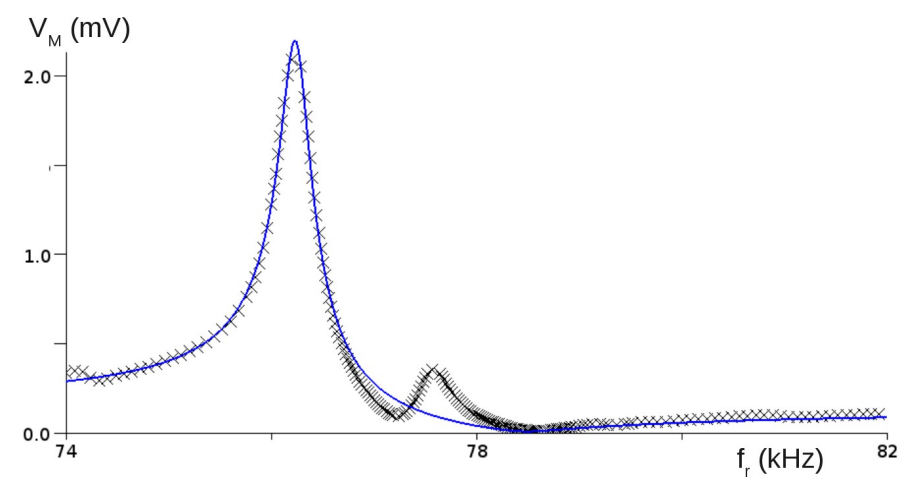

Figure 7 : Amplitudes as a function of the frequency for $1350 \mathrm{~A} / \mathrm{m}$, as cast 2605C ribbon

The evolutions of $\mathrm{f}_{\mathrm{r}}, \mathrm{f}_{\mathrm{a}}, \mathrm{Y}, \mathrm{k}_{33}, \eta, \mathrm{d}_{33}$ and $\varepsilon$ are plotted for an as cast and a $10 \mathrm{kA} / \mathrm{m}$ transverse field annealed ribbon in Figures 8 and 9, respectively (those of the zero-field annealed ribbon, not shown here, are intermediate.) One notes that $\mathrm{f}_{\mathrm{r}}$ goes through a minimum which decreases with heat treatment in relation with the softening (this is often refereed in literature as $\Delta \mathrm{E}$ effect), while $\mathrm{f}_{\mathrm{a}}$ is increasing, with an inflection point corresponding to the minimum of $\mathrm{f}_{\mathrm{r}}$. In addition, $\mathrm{k}_{33}$ passes through a maximum, the value of which is increasing up to 0,55 after field annealing. Such a value remains smaller than that given in literature $(0,97$ [12]) but the annealing may have to be improved. We checked that the evolutions of $\mu(\mathrm{H})$ and $\mathrm{V}_{\mathrm{Mo}}(\mathrm{H})$ are similar, allowing to discuss the magnetostriction curves $\varepsilon(\mathrm{H})$. The values of saturation magnetostriction are estimated at 20,28 and $32 \mathrm{ppm}$, for the as cast, zero-field and transverse-field annealed ribbons, respectively, in fair agreement with the expected value of $30 \mathrm{ppm}$ [12].
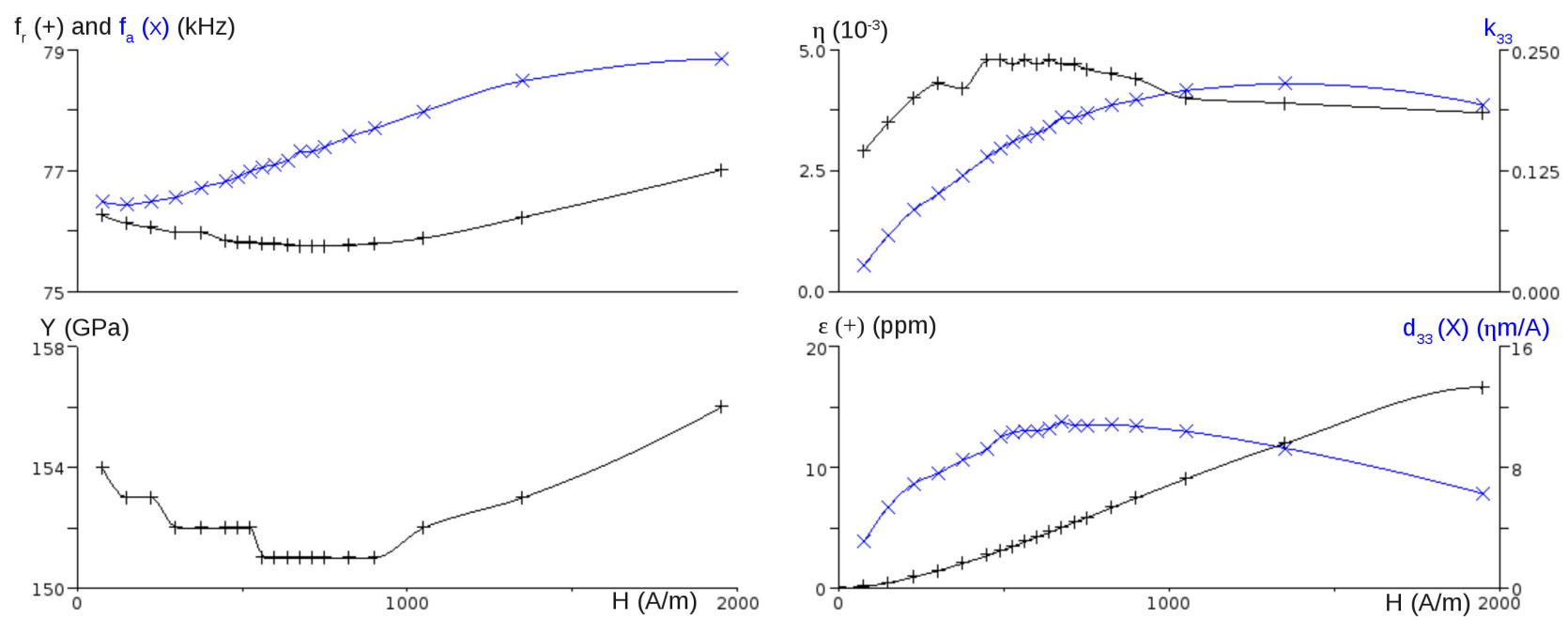

Figure 8: evolution of $\mathrm{f}_{\mathrm{r}}, \mathrm{f}_{\mathrm{a}}, \mathrm{Y}, \mathrm{k}_{33}, \eta, \mathrm{d}_{33}$ and $\varepsilon$ as function of DC field for 2605SC as cast 

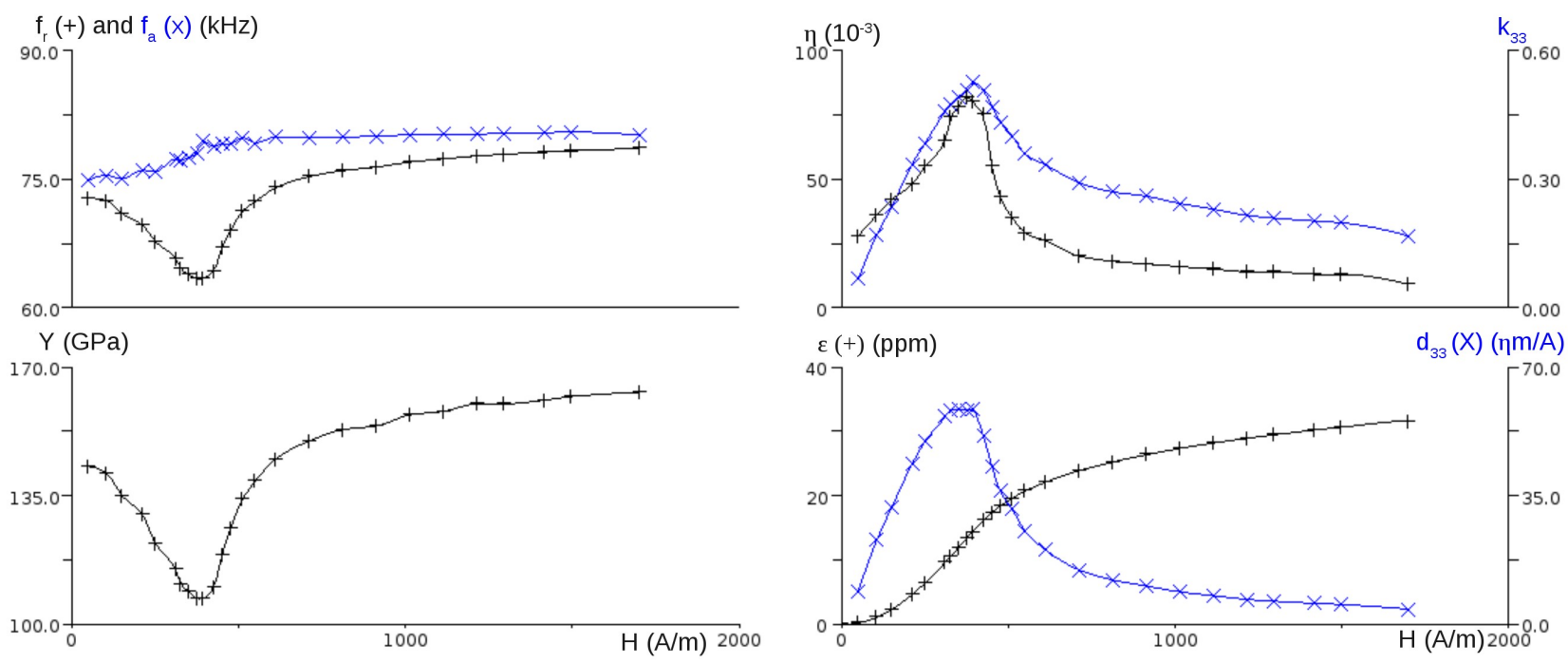

Figure 9: evolution of $\mathrm{f}_{\mathrm{r}}, \mathrm{f}_{\mathrm{a}}, \mathrm{Y}, \mathrm{k}_{33}, \eta, \mathrm{d}_{33}$ and $\varepsilon$ as function of DC field for 2605SC annealed under field.

\subsection{Measurements with 2826}

According to annealing conditions detailed in section 3.2, 2826 ribbons have been studied as a function of frequency. Figure 10 illustrates the quite good fit in agreement with the rectangular shape of the ribbon which was easily obtained compared to iron-based ribbons, because Ni based amorphous alloys are much less brittle.

The evolutions of $\mathrm{f}_{\mathrm{r}}, \mathrm{f}_{\mathrm{a}}, \mathrm{Y}, \mathrm{k}_{33}, \eta, \mathrm{d}_{33}$ and $\varepsilon$ are plotted for one as-cast and two transverse-field annealed ribbons (10 and $800 \mathrm{kA} / \mathrm{m})$ in Figures 11 and 12, respectively. One observes similar features as for 2605SC but the values differ - particularly $\mathrm{k}_{33}$ which increases up to 0,3 after transverse-field annealing - from that found in literature (0,5 [21]). The values of saturation magnetostriction estimated at 8 and $12 \mathrm{ppm}$, for the as cast and transverse-field annealed ribbons respectively, are in fair agreement with the expected value of $12 \mathrm{ppm}$ [12][17]. The difference observed Fig.12 for the samples annealed in different fields is in line with the higher induced anisotropy when annealed in stronger field.

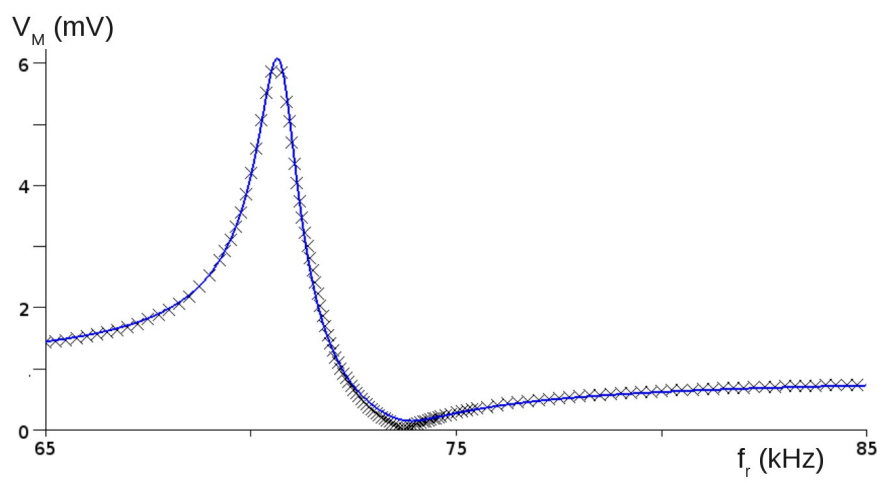

Figure 10: Amplitudes as a function of the frequency for $550 \mathrm{~A} / \mathrm{m}$, on the as cast 2826 ribbon 

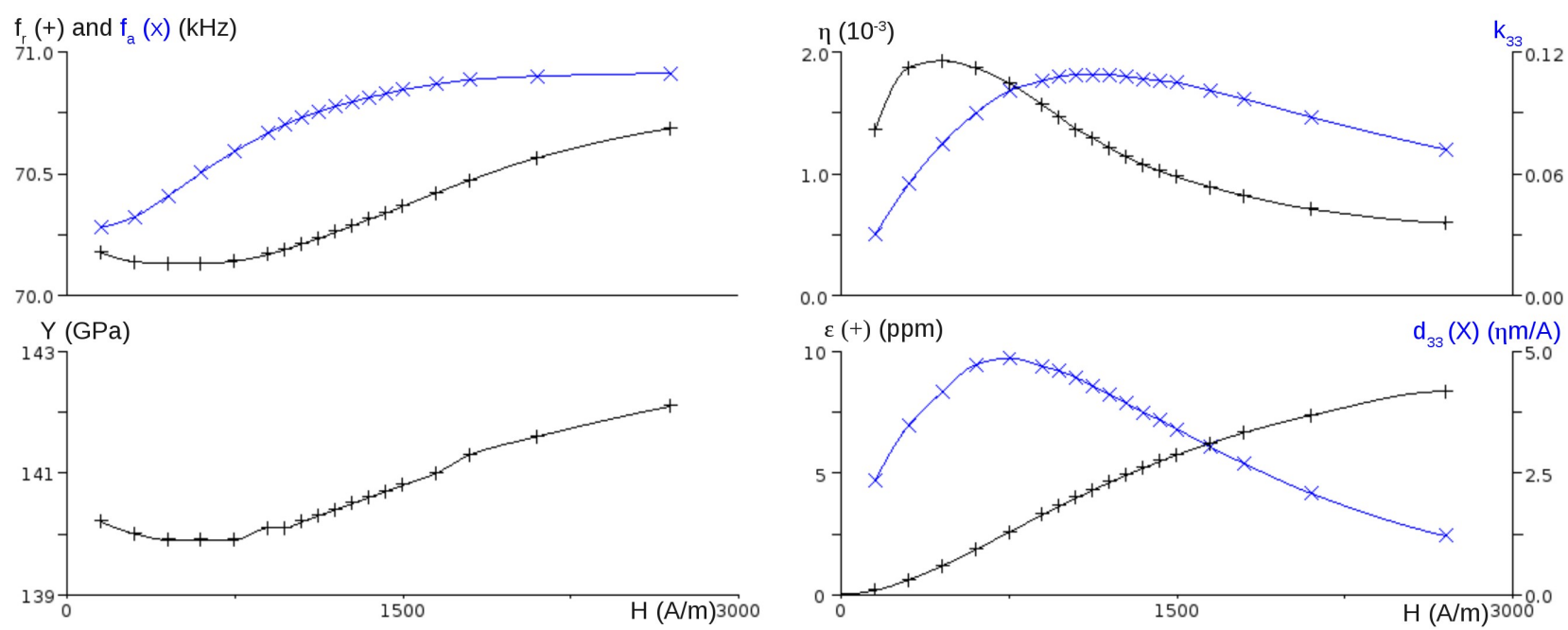

Figure 11: evolution of $f_{r}, f_{a}, Y, k_{33}, \eta, d_{33}$ and $\varepsilon$ as function of DC field for 2826 as cast ribbon
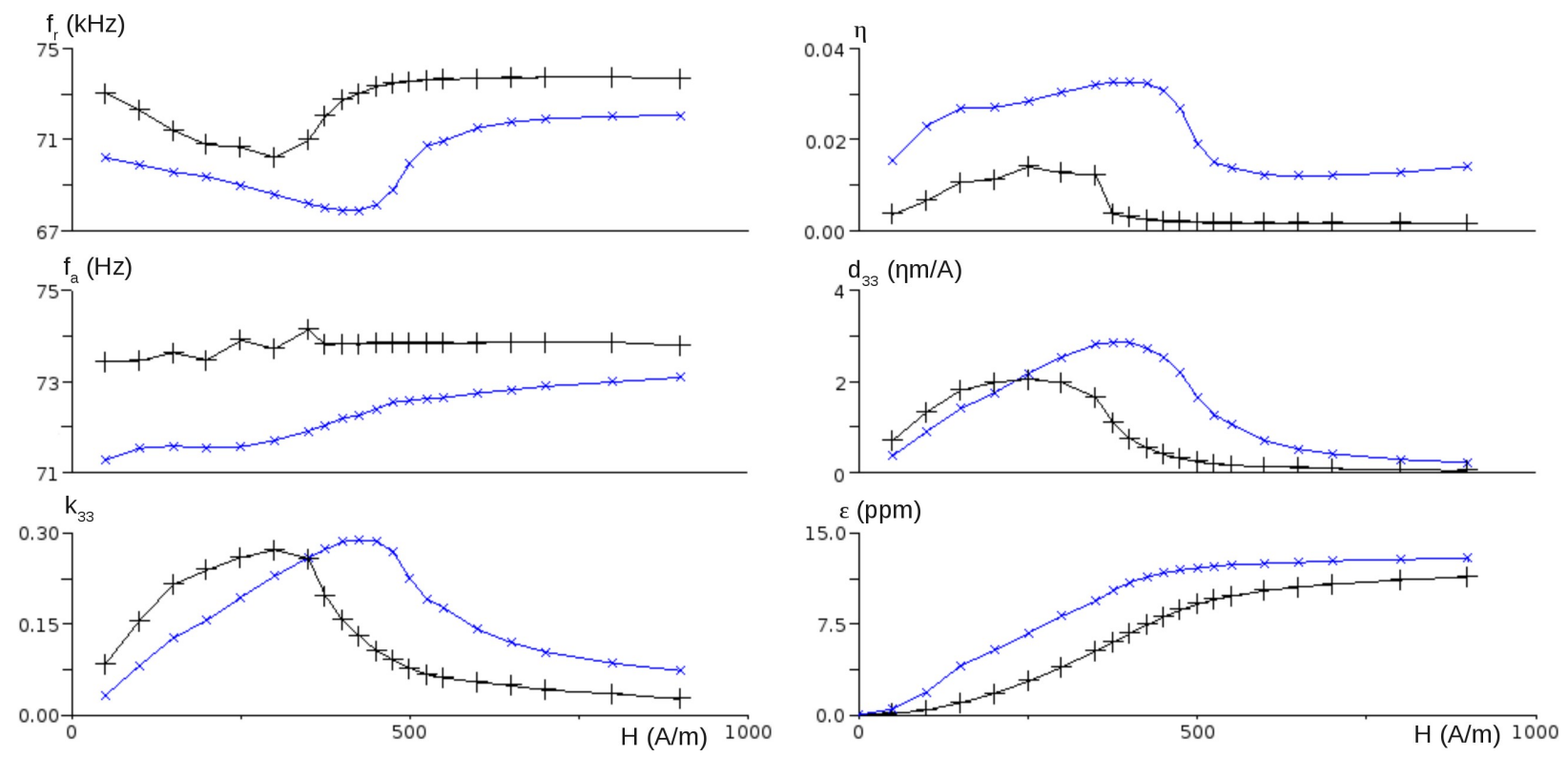

Figure 12: evolution of $f_{r}, f_{a}, Y, k_{33}, \eta, d_{33}$ and $\varepsilon$ as function of DC field for 2826 annealed under 800kA/m (black) and 10kA/m (blue)

\subsection{Effect of length on 2826 ribbons}

We studied the effect of the length of the magnetostrictive resonator to validate the present method. It is important to emphasize that the transverse field annealed 2605SC ribbon remains the best choice from magnetoelastic point of view, but its brittleness is problematic for cutting (see 5.1).

Consequently, 2826 ribbons into 3 different lengths of 25, 30 and $35 \mathrm{~mm}$ in the as-cast state and annealed under vacuum in a transverse field of $10 \mathrm{kA} / \mathrm{m}$. Indeed, such a treatment which improves $k_{33}$, is easy to reproduce and should give rise to similar behaviours.

As is shown in figure 13, the results are quite independent of the ribbons length, except a small shift towards lower field as the length increasesin relation with the demagnetizing coefficient despite the same length to width ratio was keptbecause the thickness remains constant.

These different measurements demonstrate unambiguously that the model is valid for amorphous ribbons, and thus offersa new method to estimate the value of magnetomechanical coefficient $\mathrm{k}_{33}$ and the magnetostriction coefficient dependence on field of free ribbons. 

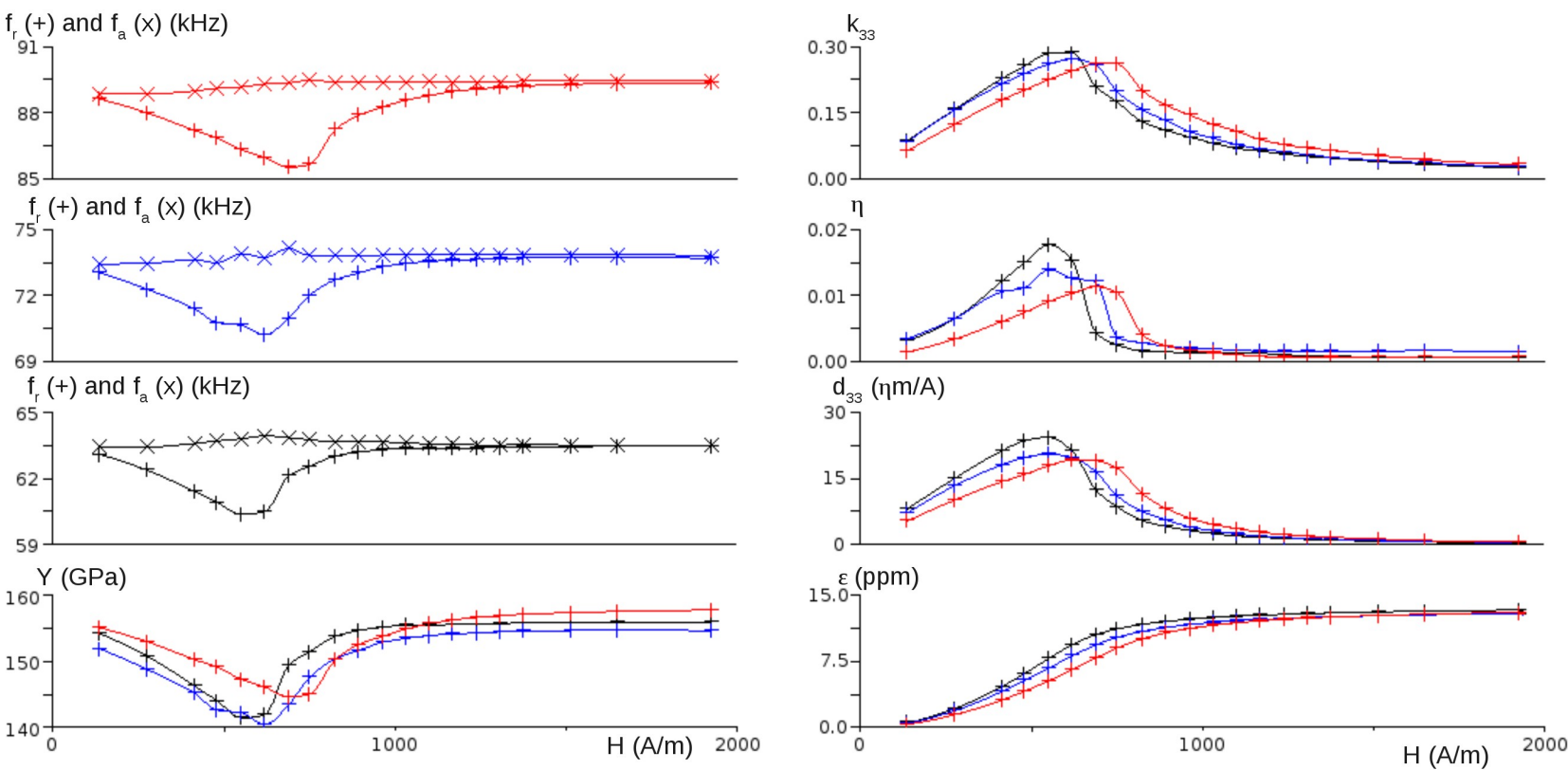

Figure 13: evolution of $\mathrm{f}_{\mathrm{r}}, \mathrm{f}_{\mathrm{a}}, \mathrm{Y}, \mathrm{k}_{33}, \eta, \mathrm{V}_{\mathrm{M} 0}, \mathrm{~V}_{\max }, \mathrm{B}, \mu, \mathrm{d}_{33}$ and $\varepsilon$ as function of DC field for 2826 annealed under 10kA/m , length of ribbon in red $25 \mathrm{~mm}$, in blue 30 and in black 35.

\section{Nickel}

The main objective is now to check whether the present model can be applied to Ni which is crystalline and magnetically harder than amorphous ribbons (see a part of the hysteresis loop in Figure 14) : the measurements were carried out on a 30mm long, $6 \mathrm{~mm}$ wide and $0.25 \mathrm{~mm}$ thick nickel foil. The spectra for $2000 \mathrm{~A} / \mathrm{m}$ and $8000 \mathrm{~A} / \mathrm{m}$ are given in the insets of Figure 14: such values correspond to non reversible magnetic and saturated states (in agreement with the width of the hysteresis loop) and .

One can conclude that the curves are well described if the bias field is sufficient to reach the reversible part of the hysteresis loop (approach to saturation) : such a feature differs from that encountered for soft amorphous alloys, showing that a very small hysteresis is necessary to use the present model. As a consequence, this method is not suitable for the determination of the magnetostriction field as a function of field, but remains useful or the determination of the coupling coefficient close to the saturation.

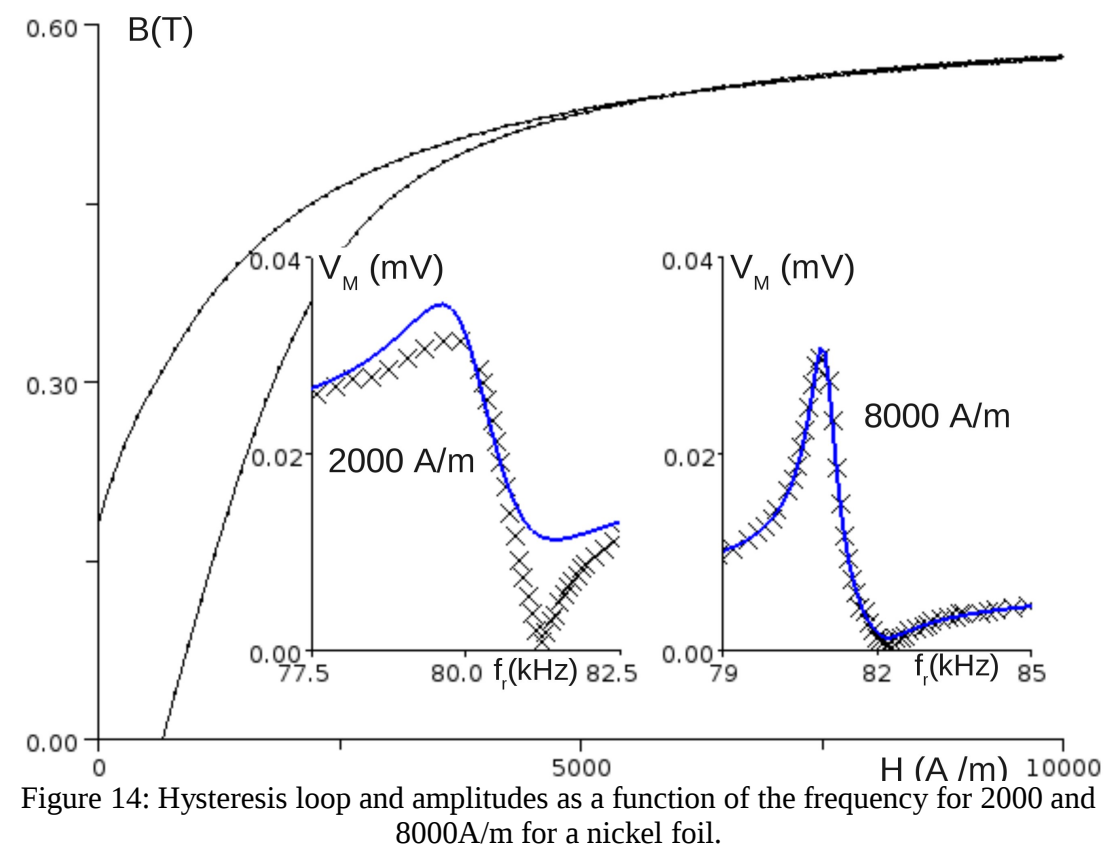




\section{Advantages over usual methods}

The present technique which is based on magnetoelastic resonance is well suitable to measure magneto-mechanical coupling coefficient $\mathrm{k}_{33}$ and then to establish the magnetostriction curve characteristic of an amorphous ribbon. It is important to emphasize that such an approach is easy to implement, rather cheap, can be used for routine measurements: it becomes thus a competing alternative technique to current methods.

\subsection{Strain gauges [19]}

Strain gauges consist of a thin meander-shaped film the resistance of which changes with the length. This change of resistance is usually measured by a Wheatstone bridge. As the gauge is glued to the sample, the measured strain corresponds to that of the structure gauge+glue+sample . In the case of crystalline materials, the use of strain gauges remains the most common route to measure the magnetostrictive coefficient, but the contact gives rise two several problems for thin ribbons. The first one originates from the fact that this method does not allow routine measurements as gauges glued cannot be removed, so the samples are out of further use. The second one lies on the change of the elastic properties induced by the contact: to reduce such an effect, micro-strain gauge have to be used, but their implementation becomes highly complicated. In addition, magnetomechanical coupling coefficient $\mathrm{k}_{33}$ cannot be strictly estimated using this method.

\subsection{Optical measurements [18]}

The principle is based on the changes of samples length which vary the optical power transmitted to an optical fibre, thus requiring a reflecting surface. Clamping a miror at the edge ot a ribbon results in a mechanical load inducing in turn a change of magneto-elastic properties. In addition, this optical approach requires also calibration which remains a delicate task and the use of quite specific equipment. As in previous case, this method does not allow the magneto-mechanical coupling coefficient $\mathrm{k}_{33}$ to be estimated.

\subsection{Capacitance method [22][19]}

The capacitance method which is expected to be the more sensitive, is based on change in capacitance induced by a change of length, which is transmitted over a mechanical system to a capacitor set-up. The change in capacitance is converted into a voltage proportional to the change in length by means of either a Wheastone bridge-like (with capacitors), or an oscillator. The sign of the magnetostriction is discernible according to the increase or decrease in voltage but coefficient $\mathrm{k}_{33}$ cannot be estimated. It is important to note that the drawbacks of the present method are very similar to those of strain gauge one.

\subsection{Flexibility of the proposed technique}

As is described as 3.1, our approach requires only a set-up comprising polarization and excitations coils ( possibly one for both), and two pick-up coils, which can be also designed to get hysteresis loops. Consequently, as the electronic equipment consists mainly of a single analyser (a computer can be implemented to make automatic measurements), such a low cost device can be easily built in most of laboratories working on amorphous magnetic ribbons. In addition, the measurements obtained by such an approach are done on a free ribbon, making it a non destructive technique and avoiding intrinsic method errors, giving big advantages over previously mentioned techniques. In 
addition, one gets an accurate estimate of magneto-mechanical coupling coefficient $\mathrm{k}_{33}$ and of magnetostriction curves on ribbon-shaped samples, that is a crucial novelty to the best of our knowledge.

\section{Conclusions}

A new model which takes into account the damping in magnetelastic resonators has been successfully applied to soft amorphous ribbons and has originated the development of a new measurement technique based on the magnetomechanical resonance. It allows to estimate easily magnetoelastic coefficient, $\mathrm{k}_{33}$, Young's modulus and to establish magnetostriction curves, keeping the ribbon free from any mechanical stress. According to literature, these figures are usually rather difficult to measure and requires at least three different experimental set-up. It is important to note that the present technique which is rather cheap andnon destructive can be used as routine approach for ribbon shaped samples, especially amorphous ribbons, since it requires both low hysteresis and mechanical losses. In addition, it has been shown that the estimation of $k_{33}$ cannot directly result

from the ratio of resonance and anti-resonance frequencies, contrarily to usual formula $k_{33}{ }^{2}=1-\frac{f_{r}}{f_{a}}$ or $k_{33}{ }^{2}=\frac{\pi^{2}}{8}\left(1-\frac{f_{r}^{2}}{f_{a}^{2}}\right)$, as reported [1] and [23]. Indeed, $\frac{f_{r}}{f_{a}}$ does not depend only on $k_{33}$ but also on damping parameter $\eta$ originating mainly from hysteresis losses. 


\section{References}

1. K.B. Hathaway, M.L. Spano, J. Appl. Phys., 84, 1765-1767, 1984

2. J.D. Livingston, Physica Status Solidi, (a) 70, 591-596, 1982

3. C. Modzelewski, H.T. Savage, L.T. Kabacoff, A.E. Clark, IEEE Trans. Magn., MAG-17, 28372839, 1981

4. T.H. O'Dell, Physica Status Solidi, (a) 74, 565-572, 1982

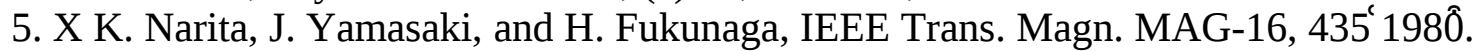

6. Y. Le Bras, F. Mazaleyrat, J. M. Greneche, Sensor Letters, 9, 1-6, 2011

7. J. Gutierrez, J.M. Barandiaran, O. Nielsen , Physica Status Solidi, (a) 111, 279-283, 1989

8. J.M. Barandiaran, J. Gutierrez, C. Gomez-Polo , Sensors and Actuators, 81, 154-157, 2000

9. J. Gutiérrez,A. García-Arribas, J. S. Garitaonaindia, J. M. Barandiaran and P. T. Squire, Journal of Magnetism and Magnetic Materials, 157-158, 543-544, 1996

10. G. Herzer, Zeitschrift für Metallkunde, 93, 978-982, 2002

11. G. Herzer, patent, G08B 13/24, WO 99/13442, 1999

12. E. Du Tremolet De Lacheisserie, Collection Grenoble Sciences, in Magnétisme (tome 1), Chapter 12, pp363-384, 1999

13. J.M. Greneche, M. Henry and F. Varret, J. Magn. Magn. Mater., 26, 153-156, 1982

14. J.M. Greneche and F. Varret, J. Phys. C: Solid State Physics, 15, 5333-5344, 1982

15. J.M. Greneche and F. Varret, J. Phys. Lettres, 43, L233-237, 1982

16. E. Du Tremolet De Lacheisserie, Collection Grenoble Sciences, in Magnétisme (tome 2), Chapter 18, pp213-235, 1999

17 MetglasTM Inc., http://www.metglas.com/products/page5_1_2_7.htm

18. P.T. Squire, M R J Gibbs, Fibre-optic dilatometer for measuring magnetostriction in ribbon samples, (1987)

19. R.Grössinger, H.Sassik, D.Holzer, N.Pillmayr, Accurate measurement of the magnetostriction of soft magnetic material,

Technical Report

20. R. O’Handley, Modern Magnetic Materials: Principles and Applications, (2000)

21. P.M. Anderson, J. Appl. Phys., 53, 8101-8103, 1982

22. E. Klokholm, Magnetics, IEEE Trans. Magn., 12, Issue: 6, 819 - 821,1976

23. E. du Trémolet de Lacheisserie, Magnetostriction, Theory and Applications of

Magnetoelasticity, CRC Press, Amsterdam, 241-247, (1993) 